\title{
Slimane Touhami, La part de l'œil. Une ethnologie du Maghreb de France
}

Paris, Éditions du Comité des Travaux Historiques et Scientifiques, 2010, $280 \mathrm{p}$.

Jean-Bruno Renard

\section{CpenEdition}

Journals

Édition électronique

URL : http://journals.openedition.org/assr/23575

DOI : $10.4000 /$ assr.23575

ISSN : $1777-5825$

Éditeur

Éditions de l'EHESS

Édition imprimée

Date de publication : 31 décembre 2011

Pagination : 285

ISBN : 9782713223273

ISSN : 0335-5985

Référence électronique

Jean-Bruno Renard, «Slimane Touhami, La part de l'œil. Une ethnologie du Maghreb de France », Archives de sciences sociales des religions [En ligne], 156 | octobre-décembre 2011, document 156-110, mis en ligne le 26 mars 2012, consulté le 21 septembre 2020. URL : http://journals.openedition.org/ assr/23575; DOI : https://doi.org/10.4000/assr.23575

Ce document a été généré automatiquement le 21 septembre 2020

(c) Archives de sciences sociales des religions 


\title{
Slimane Touhami, La part de l'œil. Une ethnologie du Maghreb de France
}

Paris, Éditions du Comité des Travaux Historiques et Scientifiques, 2010, $280 \mathrm{p}$.

\author{
Jean-Bruno Renard
}

\section{RÉFÉRENCE}

Slimane TouнAmi, La part de l'œil. Une ethnologie du Maghreb de France, Paris, Éditions du Comité des Travaux Historiques et Scientifiques, 2010, 280 p.

1 Tiré d'une thèse de doctorat en anthropologie préparée sous la direction de Claudine Vassas et soutenue en 2007 à l'EHESS, ce bel ouvrage traite des croyances et des pratiques autour du « mauvais œil » (le aïn) dans la population d'origine magrébine de Toulouse. Slimane Touhami s'inscrit dans une ethnologie du monde contemporain (Gérard Althabe, Jean Copans) qu'il applique aux immigrés et aux enfants d'immigrés, reprochant à juste titre à la sociologie de s'être approprié la question de l'immigration en négligeant la dimension culturelle, qu'elle réduit soit à une "identité immuable " (p.10), soit à un «néant culturel dans lequel s'oublieraient les migrants et leurs enfants » (id.) L'auteur cite Denys Cuche, qui écrit à propos des immigrés : «L'examen de leur condition sociale n'est pas suffisant à une bonne compréhension de leurs pratiques. L'analyse culturelle est nécessaire pour saisir la cohérence symbolique de l'ensemble de ces pratiques» (La notion de culture, 1996, p. 112, cité p. 11). Le motif du «mauvais œil » est un puissant révélateur de cet univers symbolique, du sentiment identitaire, de l'espace privé et domestique, des interrogations sur le religieux, le changement culturel et l'acculturation.

2 À l'instar de Jeanne Favret-Saada travaillant sur la sorcellerie dans l'ouest de la France, S. Touhami s'est retrouvé impliqué dans son objet : il devenait malgré lui un spécialiste 
de la «science du mauvais œil » et a souvent été sollicité par des mères demandant des « recettes » magiques qu'elles ne connaissaient pas ou des précisions sur telle ou telle manière de faire. Résultat de cette ethnologie par immersion, La part de l'œil est un excellent ouvrage, à l'écriture agréable et sans jargon, qui apporte une riche contribution à l'étude des croyances magico-religieuses autour du « mauvais œil » ainsi qu'à l'analyse de l'émergence d'une culture magrébine «de France » (et non «en France », pour bien souligner qu'il s'agit d'une recomposition culturelle originale et non d'une culture purement et simplement importée).

3 L'un des thèmes forts de l'ouvrage est le rôle des femmes. Selon l'auteur, un élément crucial de l'immigration maghrébine en France a été le regroupement familial, dans les années 1975-1976, inaugurant "l'heure des mères" (p. 72) qui succédait à une immigration masculine et souvent temporaire. Les femmes vont être des "passeuses " entre la culture d'origine et la culture d'exil. Cette "sociabilité féminine ", qui va bien au-delà des invitations à prendre le thé à la menthe et à déguster des gâteaux, est surtout le lieu de transmission de croyances et de pratiques, en particulier autour du «mauvais œil ». Des symboles forts - la khemsa, improprement appelée «main de Fatma ", le pentagramme, un dab (gros lézard empaillé), une pièce de monnaie trouée, un cauri, un papier où est inscrit un verset coranique, souvent le verset du Trône (deuxième sourate, verset 255 en numérotation orientale des versets), une fumigation d'encens - protégeront les enfants, la mariée, la maison, le commerce, la voiture, la mobylette, contre l'œil envieux. Et si malgré tout le mal frappe, les femmes savent lutter contre lui par l'usage du sel ou de la pierre d'alun (éléments qui captent et emprisonnent le mal comme ils ont la capacité d'absorber l'humidité), ou par des rituels magico-divinatoires tels que l'étonnante technique de l'empan (p. 165-168) qui consiste à appliquer plusieurs fois une mesure (par exemple l'écart entre le pouce et l'index) sur le corps du patient pour diagnostiquer puis guérir une attaque par le mauvais œil. L'auteur appartient à une génération d'anthropologues qui ne se sentent pas obligés de jeter dans «la poubelle de l'histoire» une ethnologie coloniale du Maghreb (Edward Westermarck, Edmond Doutté, Émile Mauchamps, Jean Servier) qui, débarrassée de ses voiles idéologiques, révèle des trésors de données ethnographiques permettant de comprendre des comportements observés aujourd'hui. Pour S. Touhami, la tradition n'est ni fixe, ni «inventée» comme le veut une certaine mode intellectuelle, mais bien en continuelle «réinvention». Ainsi des objets de consommation modernes mais usagés sont "recyclés " comme amulettes contre le mauvais œil, par exemple le pneu d'automobile ou le CD, tous deux symboles oculaires. Les bâtonnets d'encens made in China se substituent à la résine de benjoin. Si les tatouages corporels ou le dab empaillé tendent à disparaître en France, la khemsa se répand comme porte-bonheur partagé par les musulmans, les juifs, les chrétiens et même les incroyants. Le fer à cheval, talisman commun aux deux rives de la Méditerranée, devient un bijou.

4 Si la conception du « mauvais œil » n'a guère changé, le «fascinateur » tend à ne plus être un marginal, un étranger ou un membre d'une autre tribu, il s'est dépersonnalisé, mais, devenu anonyme, il n'en est pas moins dangereux car il est partout. S. Touhami explique le recours à la tradition autour du aïn comme un moyen de surmonter le déchirement de l'exil et la crainte du monde environnant. La tradition modernisée permet l'adaptation à la culture d'accueil. 
5 À l'encontre d'une vision naturaliste des croyances traditionnelles, qui les associe au milieu rural, Slimane Touhami montre que le mauvais œil - et les êtres invisibles, génies (jnouns), démons (shayatines) et anges (malaikas), auxquels il consacre plusieurs belles pages - persistent dans un cadre urbain et technologique: "Derrière l'atmosphère souvent pesante des grands ensembles de la périphérie toulousaine (...) il existe un mode enchanté (...) Dans cet endroit que certains aimeraient croire englué dans le degré zéro de l'imaginaire, l'espace d'un religieux venu d'ailleurs a curieusement fini par occuper les moindres interstices d'un habitat souvent décrié comme inhumain : les familles de jnouns ont quitté la médina de Meknès pour repeupler les conduites d'eaux usées de la cité Amouroux. Les "Maîtres de la maison" errent la nuit dans la cuisine pour se nourrir d'un quignon de pain industriel acheté au discounter de quartier. Les anges descendent dans les appartements du quartier de la Reynerie lors de la "Nuit du Destin". La menace du mauvais œil hante l'esprit de l'étudiante du Mirail à la veille de ses partiels... » (p. 255). 